\title{
Older Adults and Email Use: The challenges facing interface co-design
}

\author{
SÓNIA DE ALMEIDA FERREIRA, School of Education, Polytechnic Institute of \\ Viseu
}

ANA ISABEL VELOSO \& ÓSCAR MEALHA, University of Aveiro - DIGIMEDIA

\section{ABSTRACT}

Faced with a rapidly ageing society and with constant technological progression, studies focused on fostering communicative action and reducing social isolation have become increasingly relevant. This paper presents a proposal of a graphical interface for an asynchronous communication service aimed at older adults, which was tested in different user contexts - both in Portugal and the United States of America. The main aims of this study are to determine to what extent the participation of older adults in the development of an email service can influence its usability and the design of a simplified interface. The usability results provide consistent clues as to how the technical development of an email service for older adults should proceed. We conclude that we should not design an email interface so as to be completely different from existing ones. Rather, we chose to improve its usability and simplify the entire process of using an email service.

\section{KEYWORDS}

asynchronous communication, computer-mediated communication, email, older adults, usability

\section{Introduction}

The impact of ICT (information and communication technologies) is not the same in all sectors of society. At the macro social level, for example, access depends on social, historical and organizational variables within the personal context of each individual. At the micro social level, the impact on the family, viewed as an organization, will also differ for each of its members, whether they are parents, children or grandparents. These differences are the result of specific variables, in constant flux, acting on each individual's history, and in the particular context of each individual's development (Lima 2010). It is widely agreed that an ageing population is exposed to greater vulnerability because of biopsychosocial changes associated with individual ageing (Pires 2008; Xie 2008; Bengtson et al. 2009; Brossoie, 2009; Pfeil, Zaphiris, \& Wilson 2009; Saxon, Etten, \& Perkins 2015). It should be noted that this is a heterogeneous process and various types of health loss and maintenance cannot be neglected. The importance of involvement in physical, mental and social activities in order to maintain and restore individual functions in older adults is generally accepted (Guerreiro 2005; Vaz-Serra 2006). 
Facilitating access to social, cultural and leisure interaction is thus seen as a necessity (Santos \& Paúl 2006). But considering the low levels of academic education in the elderly population ( $>65$ years old) (Espanha 2011) and the rapid development of ICT (Cziko \& Park 2003; Hu, Wood, Smith, \& Westbrook 2004; Boyd \& Ellison 2007; Kim, Kim, Park, \& Rice 2007; Xie 2008), the factors that appear to mostly affect older adults' use of the Internet and ICT are interface design (Pfeil et al. 2009; Ferreira, 2013) and the inherent limitations of ageing (see table 1) (Pires 2008; Xie 2008; Pfeil et al. 2009).

Online environments should, therefore, be developed to reflect the characteristics of this particular public, as well as the amount of resources that they are able to use on the Internet. It is thus necessary to promote the digital inclusion (Guerrieri, Bentivegna, \& Meliciani 2010; Zickuhr \& Madden 2012; Prendergast \& Garattini 2015) of this age group through interfaces, which enable equal and fair access to digitally available content.

To ensure that suitable senior interfaces are appropriately conceptualized, it is important to understand the consequences of changes in age-related interaction with computers and digital environments. Table 1 outlines these potential changes (Sales \& Cybis 2003; Preece, Rogers, \& Sharp, 2005; Czaja \& Sharit 2013). An appropriate understanding of these factors helps in identifying specific elements that can be introduced during the development of communication services, particularly in interfaces.

The coherent treatment of both the content and design of an intuitive interface can contribute to the inclusion of a greater number of users, for reasons of access and ease of use.

Several studies demonstrated that email is still the most predominant communication service used by older adults online (Czaja \& Lee 2001; UMIC 2010; Madden 2010; Zickuhr \& Madden 2012; Morrison \& Barnett 2013). The Pew Research Center report (Zickuhr \& Madden 2012) indicates that $53 \%$ of American seniors use the Internet or email. Different modes of CMC (computer-mediated communication), specifically voice chat, online forum and IM (instant messaging) - in an older adult context - are used for different purposes. Voice chat is predominantly used to talk with participants and share topics such as music preferences. According to these users, in this context, they form a sense of belonging and a social connection, facilitating bonds of fellowship and, occasionally, emotional support (Xie 2008). Similar studies (e.g. Wright 2000; Kanayama 2003) highlight the manifestation of supportive relationships among seniors. In turn, the online forum serves the purpose of informative support to help participants resolve issues with the computer. IM services facilitate and foster positive intimate relations (Gross, Juvonen, \& Gable 2002; Hu, Wood, Smith, \& Westbrook 2004). The main reason for these results is that IM ensures genuine interaction while protecting privacy. 
Regarding how older adults feel in a technological society, they are often excluded both in terms of access and ownership. Associated with the biopsychosocial changes caused by age are the lack of access opportunities, resulting from economic variables, the functionality of technology and issues regarding its design and usability (Nielsen 2002; Preece et al. 2005; Rice \& Alm 2008; Pfeil et al. 2009; Czaja \& Sharit 2013). It is important to provide research-based guidelines for website design that consider the main interaction difficulties in order to make websites more user-friendly for all adults (Nielsen 2002; Bosman et al. 2002; Zaphiris, Ghiawadwala \& Mughal 2005).

Such guidelines would include the following topics: 1) the number of stages or steps needed to complete a task should be reduced to minimize the risk of error; 2) the clickable area should include the largest possible surface; 3) body text should use a 12 or 14point, non-condensed sans-serif typeface; 4) the layout of the website should be simple and straightforward to ensure that people understand what follows next; 5) interaction between links should include feedback strategies, with color and font used to differentiate between active and visited links; 6) design strategies should facilitate the recognition of areas and tasks to do, focusing always on consistency and clearness; 7) regarding colors, there should be a good contrast between letters and background color, and in terms of seeking information, there should, whenever possible, be a domestic search engine within the website itself.

Older adult users tend to rely on external stimuli and environmental support (offered by the system) for information and memorizing correct answers, so it is important to implement a project that focuses more on the relationship between stimuli and learned responses. Furthermore, the options provided in the interface must be compatible with user profile; scrolling should be avoided as should keeping more than one window open; error messages, manuals and help should be provided; the use of icons and symbolic representations are also of particular importance and must be recognized and understood by users without any ambiguity or misunderstanding.

\begin{tabular}{|c|c|}
\hline $\begin{array}{l}\text { Changes resulting from the human } \\
\text { ageing process }\end{array}$ & $\begin{array}{l}\text { Senior Interaction - Computers and digital } \\
\text { environments }\end{array}$ \\
\hline $\begin{array}{l}\text { Visuals: difficulties in discriminat- } \\
\text { ing details of nearby objects; diffi- } \\
\text { culties in reading; decrease in } \\
\text { chromatic and light sensation; 'eye } \\
\text { strain', which decreases the quality } \\
\text { of near vision; physiological de- } \\
\text { generative processes in the retina. }\end{array}$ & $\begin{array}{l}\text { The decreased ability of vision can affect HCI } \\
\text { (Human-Computer Interaction) when: the size of } \\
\text { the fonts available in the software and / or digital } \\
\text { information environments are very small; there is } \\
\text { no significant color contrast between text and } \\
\text { background, there is insufficient lighting for read- } \\
\text { ing, the hardware does not have sufficient technol- } \\
\text { ogy to support the technologies that the software } \\
\text { needs. }\end{array}$ \\
\hline
\end{tabular}

Table 1 Human ageing and interaction with computers and digital environments (Sales \& Cybis 2003; Preece, Rogers \& Sharp 2005; Czaja \& Sharit 2013) 
Changes resulting from the human Senior Interaction - Computers and digital ageing process environments

Hearing: gradual decreases in The decrease in hearing ability can interfere with hearing ability, buzz, attention HCI when: the sounds provided by software and/or difficulties in cases of environ- digital information environments are not presented mental noise or group conversa- clearly, there is no easy or available resource to tions; low tolerance for high vol- increase/decrease the volume; videoconferencing ume and high intensity sounds. sounds, for example, have some shortcomings: there is no possibility to hear the sounds because of the overlapped noise of the surrounding environment.

Physical: Problems of osteomuscu- Affects HCI in the use of physical aspects of interlar and muscular order. action (I/O device's hardware ergonomics).

Attention: difficulties in divided Interferes with HCI when seniors need to activate attention, e.g., decreased ability to pay attention to several things at once. selective attention among many options, as well as when various elements are displayed and users cannot pay attention to all the elements; for example, various text and image deals in an electronic shopping environment.

Perception: decreased ability to Affects HCI when seniors do not recogfind figures or shapes embedded in nize/perceive mixed and/or fragmented elements complex patterns; decline in the such as text, images and sounds.

ability to recognize fragmented or incomplete objects.

Memory: Salient changes related to secondary memory, or the shortterm memory.

Learning: related changes in atten- Interferes with HCI when seniors cannot properly tion, perception and memory. use the cognitive processes of attention, perception

Language: related to the production and reception of language with regard to reading, speaking and listening.

Problem solving, planning, reasoning and decision-making: related more with the proper individual than seniors in general. and memory, impairing learning.

Affects HCI when seniors fail to memorize the features they just accessed.

Affects HCI when seniors cannot use sensory systems related to vision and hearing for language processing.

Interferes with HCI when seniors cannot handle errors in the use of software and/or digital information environment, use advanced search options to find specific information because of overloading graphics and/or text reasons.

Table 1 Human ageing and interaction with computers and digital environments (Sales \& Cybis 2003; Preece, Rogers \& Sharp 2005; Czaja \& Sharit 2013) 
Therefore, studying and developing ICT services for senior users, as proposed in this paper, is of utmost importance for communication among older adults. Knowledge of ICT and using computers is still something new for many in this age group, but the incentive to learn more is getting stronger (Nugent 2007; Hernández-Encuentra, Pousada, \& Gómez-Zúniga 2009) and the situation is changing.

The present study was designed to present a proposal for a graphical email interface for older adults - online communication area of the SEDUCE project (www.seduce.pt) and provide new knowledge for future research in this area. It seeks to fulfill the following objective: to determine whether the participation of older adults in conceptualizing an asynchronous communication service (email) - participants may engage in the exchange of ideas or information without the dependency of other participants' involvement at the same time (Mitrea \& Mitrea 2010) - can have an influence on its usability, with particular regard to the effectiveness and efficiency of its components and the satisfaction of its users.

\section{Material and methods}

The email service was developed at two Private Social Welfare Institutions (IPSS A and IPSS B) in Aveiro (Portugal), and at a public library in Maryland (USA) between December 2011 and October 2012.Participation criteria included individuals who were (i) aged over 65; (ii) motivated towards using ICT; and (iii) of normal cognitive status (dementia screening conducted by the Mini-Mental State Examination, validated in Portugal and USA). All participants signed a consent form. Table 2 outlines participants' characteristics (age, gender, years of schooling and frequency of computer use).

In order to better understand the participants' context, a questionnaire was conducted regarding these older adults' use of CMC services and computers. It is important to determine how often and where they normally use these services, whether they do so alone or not, and what activities they perform. This data was collected with a survey by questionnaire applied to all 14 seniors. Table 3 details the use of CMC services by the seniors involved in the interface design of an asynchronous communication service.

As noted, the present research pertains to the online community communication area of the SEDUCE project and presents the evaluation phase of this service. Project researchers Simões (2011) and Fonseca (2011) jointly conceptualized the first interface of an email service for the SEDUCE research project, and the seniors at IPSS A tested this first prototype. In the participatory design process, Simões (2011) used the card sorting technique while Fonseca (2011) applied the PICTIVE technique. 


\begin{tabular}{|c|c|c|c|}
\hline Code Name & Age & Gender & Years of Schooling \\
\hline \multicolumn{4}{|c|}{ IPSS A (Aveiro) } \\
\hline $\mathrm{CS}$ & 80 & $\mathrm{~F}$ & 6 years \\
\hline JB & 77 & M & 3 years \\
\hline JR & 85 & M & 4 years \\
\hline MD & 80 & $\mathrm{~F}$ & 4 years \\
\hline $\mathrm{MM}$ & 79 & $\mathrm{~F}$ & 4 years \\
\hline \multicolumn{4}{|c|}{ Public Library (Maryland) } \\
\hline $\mathrm{BH}$ & 81 & M & 9 years \\
\hline $\mathrm{CB}$ & 72 & $\mathrm{~F}$ & 9 years \\
\hline DB & 75 & M & 6 years \\
\hline $\mathrm{HC}$ & 69 & M & 4 years \\
\hline MT & 78 & $\mathrm{~F}$ & 6 years \\
\hline \multicolumn{4}{|c|}{ IPSS B (Aveiro) } \\
\hline $\mathrm{AC}$ & 79 & M & 5 years \\
\hline $\mathrm{AF}$ & 88 & M & 4 years \\
\hline $\mathrm{JF}$ & 76 & M & 4 years \\
\hline $\mathrm{NC}$ & 69 & $\mathrm{~F}$ & 7 years \\
\hline
\end{tabular}

Table 2 Participants' characteristics

(age, gender, years of schooling and frequency of computer use)

In accordance with the guidelines for the development of appropriate Web interfaces for older adult users (Bosman et al., 2002; Nielsen, 2002; Redish \& Chisnell 2004; Zaphiris et al. 2005), the most significant issues for the visual and interactive design of email are: avoiding drop down menus and scrolling; tutoring tasks; clear confirmation pages; letter size; clickable items that are easy to target and hit; and contrasting text and background colors (Bosman et al. 2002; Nielsen 2002; Zaphiris et al. 2005; Simões 2011; Ferreira, 2013).Table 4 outlines where the tests took place and the number of participants in the three prototype versions.

Using the contextual design method, we opted to carry out tasks in the three versions of the prototype-mail, focusing on the context of each user's specific use of the service (Beyer \& Holtzblatt 1999; Preece et al. 2005).

The second phase of testing took place at IPSS A and in a public library in Maryland and the third phase of testing was once again undertaken at IPSS B. The researchers used an observation grid to record the results. Data was subsequently interpreted and applied to a newly organized version of the prototype, which included the identified needs. The contextual design process thus involved first reaching an understanding through the contextual inquiry phase - by gathering information about the context of users' use of the service, following a set of predefined tasks in accordance with the 
goals set - and then co-designing work to improve the prototype according to the information obtained.

Overview of participants' use of CMC services and computers

\begin{tabular}{|c|c|c|c|c|c|}
\hline $\begin{array}{l}\text { Code } \\
\text { Name }\end{array}$ & $\begin{array}{l}\text { Computer } \\
\text { Use Fre- } \\
\text { quency }\end{array}$ & $\begin{array}{l}\text { Alone/ Accom- } \\
\text { panied }\end{array}$ & Where? & $\begin{array}{l}\text { Principal } \\
\text { activity }\end{array}$ & Other activities \\
\hline \multicolumn{6}{|c|}{ IPSS A (Aveiro) } \\
\hline $\mathrm{CS}$ & Every 3 days & Accompanied & IPSS & Write & $\begin{array}{l}\text { Use email; } \\
\text { search for in- } \\
\text { formation }\end{array}$ \\
\hline JB & Every 3 days & Accompanied & IPSS and home & Write & Use email; \\
\hline JR & Every 3 days & Accompanied & IPSS & Write & $\begin{array}{l}\text { Use email; } \\
\text { search for in- } \\
\text { formation }\end{array}$ \\
\hline MD & Every 3 days & Accompanied & IPSS & Write & $\begin{array}{l}\text { Use email; } \\
\text { search for in- } \\
\text { formation }\end{array}$ \\
\hline MM & Every 3 days & Accompanied & IPSS & Write & Use email \\
\hline \multicolumn{6}{|c|}{ Public Library (Maryland) } \\
\hline $\mathrm{BH}$ & Every day & Alone & Public Library & Use email & Read news \\
\hline $\mathrm{CB}$ & Every 3 days & Alone & Home & Use email & $\begin{array}{l}\text { Write; read } \\
\text { news }\end{array}$ \\
\hline DB & Every 3 days & Alone & Home & Find Job & $\begin{array}{l}\text { Search for } \\
\text { friends; Play }\end{array}$ \\
\hline $\mathrm{HC}$ & Every day & Alone & Home & Write & $\begin{array}{l}\text { Use chat and } \\
\text { email; search } \\
\text { health infor- } \\
\text { mation }\end{array}$ \\
\hline MT & Every day & Alone & Home & Write & Play \\
\hline \multicolumn{6}{|c|}{ IPSS B (Aveiro) } \\
\hline $\mathrm{AC}$ & Every 3 days & Accompanied & IPSS & Write & Use email \\
\hline $\mathrm{AF}$ & Every 3 days & Accompanied & IPSS & $\begin{array}{l}\text { Write; use } \\
\text { email }\end{array}$ & Read news \\
\hline JF & Every 3 days & Accompanied & IPSS & Write & Use email \\
\hline $\mathrm{NC}$ & Every 3 days & Accompanied & IPSS & Write & Use email \\
\hline
\end{tabular}

Table 3 Overview of participants' use of CMC services and computers 


\begin{tabular}{llll}
$\begin{array}{l}\text { Prototype } \\
\text { interface layout }\end{array}$ & Test site & $\begin{array}{l}\text { Number of } \\
\text { participants }\end{array}$ \\
\hline 1st version & IPSS A (5 seniors) & 5 \\
2sd version & IPSS A (5 seniors) & $\begin{array}{l}\text { Public library in } \\
\text { Maryland (5 seniors) }\end{array}$ & 10 \\
3td version & IPSS A (5 seniors) & IPSS B (4 seniors) & 9 \\
\hline
\end{tabular}

Table 4. Test site and number of participants in the three prototype versions

For the development of the prototype, an initial objective-oriented preparation was necessary, which required the formulation of a structured script of actions and observation. The actions contemplated: (a) read a new message; (b) reply; (c) compose a new message; (d) choose and add contacts; (e) read messages already read and; (f) read deleted messages.

Throughout all these steps, older adults had complete freedom to suggest changes.

\section{Results}

The interaction between the seniors and the first prototype ${ }^{1}$ - first phase of testing (Figures 1, 2, 3, 4 and 5) indicated the following observations and subsequent changes:

i) in the input area of the email interface (Figure 1), the clickable area to open messages should include the largest possible surface, including a photo, name and subject (Bosman et al. 2002; Nielsen 2002; Zaphiris, et al. 2005). The test participants rarely used the 'view' button to open messages. They clicked throughout the area that identifies the message (picture, name, subject, date); in the same window, the 'next' and 'previous' buttons to view more posts did not work. It was, therefore, necessary to consider an alternative to scrolling (Bosman et al. 2002; Nielsen 2002; Zaphiris et al. 2005);

ii) the participants had no difficulty in interacting with the 'read new message' (Figure 2) and 'reply' fields (Figure 3);

iii) in the 'write new message' field (Figure 4), no individuals wrote the subject of the message. When asked to explain this, they said that they were not aware of its presence and questioned its importance. For technical email reasons (content needs to be written), the subject area is required, so suggestions were requested. The use of the word 'title' was suggested as an alternative to "subject" and prevailed;

\footnotetext{
${ }^{1}$ All the profile photos used are not from real participants.
} 
iii) in the 'choose contacts' field (Figure 5), the strategy of simulating a paper ballot (like political ballot vote) worked well. However, when selecting multiple contacts, the participants did not remember whom they had already chosen. The 'accept' button to validate selected contacts did not work either.

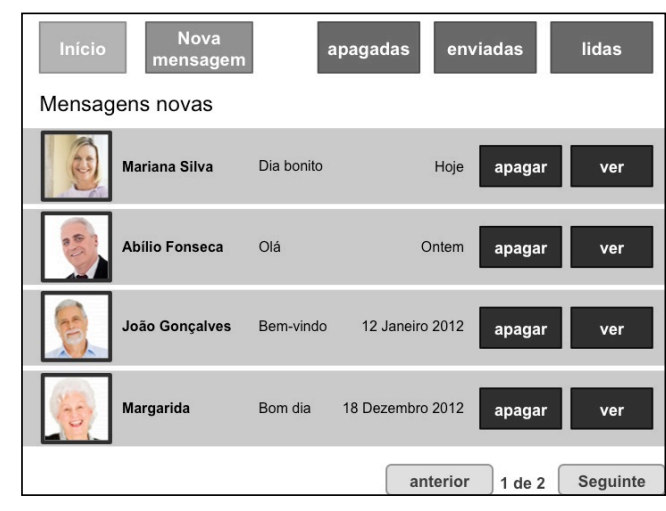

Figure 1. Interface layout of inbox area, 1st version

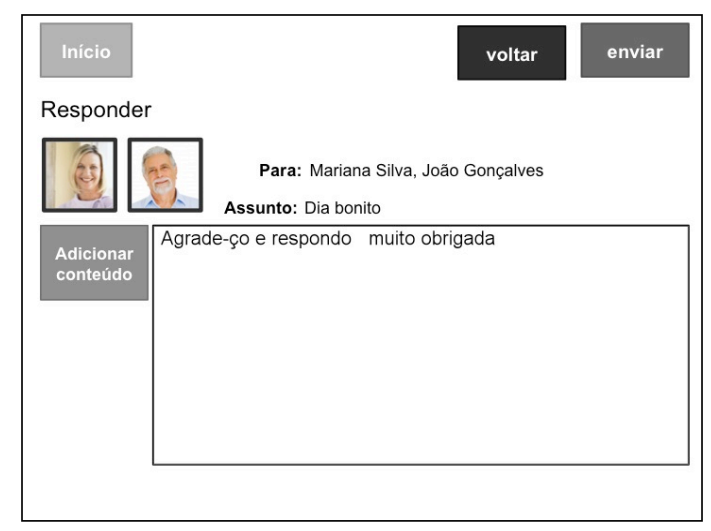

Figure 3. Interface layout of the 'reply' area, 1st version

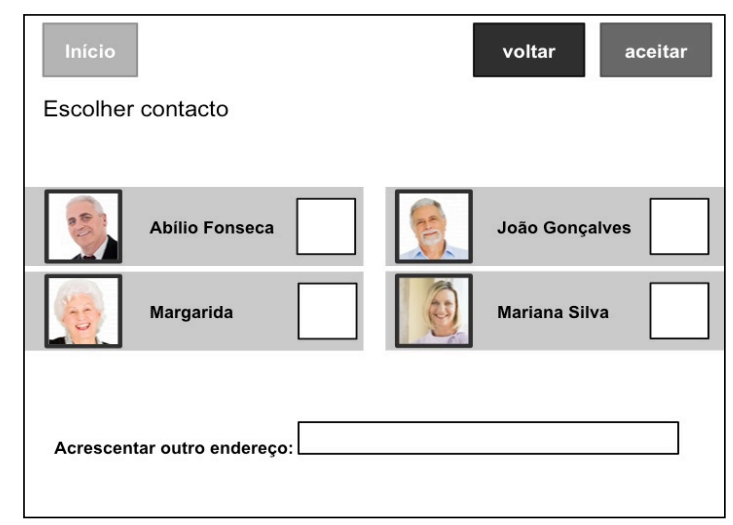

Figure 5. Interface of the 'select contacts' area, 1st version

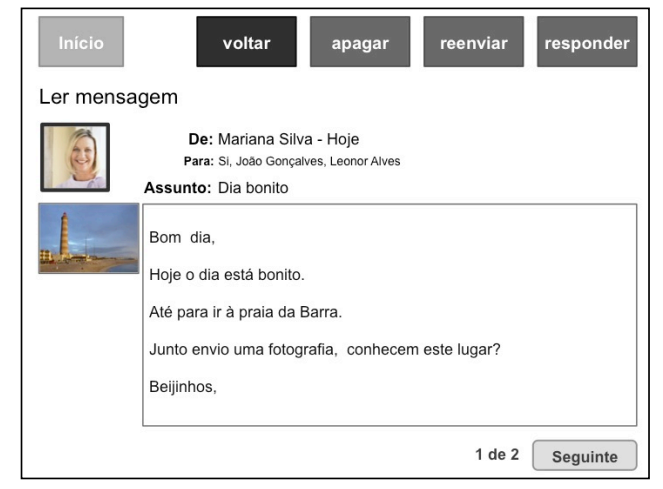

Figure 2. Interface layout of the 'read new message' area, 1st version

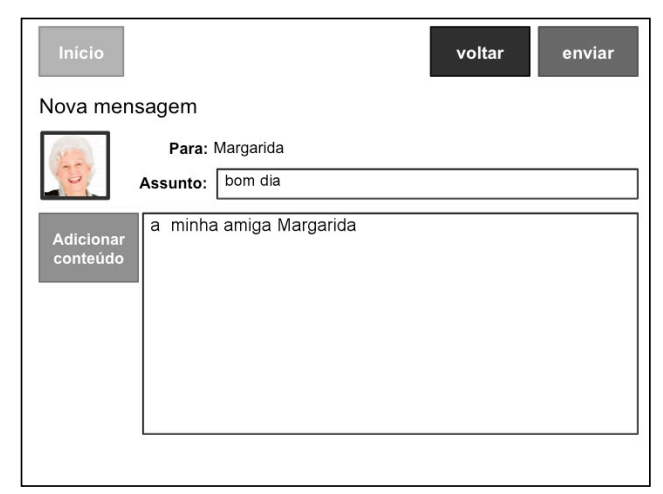

Figure 4. Interface layout of the 'write new message' area, 1st version 
After taking these findings into account, the interface was co-designed. The evaluation of the second version of the prototype by the group of older adults in Aveiro - second phase of testing -, (Figures 6, 7, 8, 9 and 10) produced the following findings:

i) in the input area of the email interface (Figure 6), the participants realized there were six messages (because of contextual information identifying the number of new messages) but only four were visible. However, they did not use the scroll. They underlined that they did not understand the concept or its presence;

ii) in the same window, Figure 6, they did not understand the meaning of the 'old messages' folder;

iii) once again the participants had no difficulty interacting with the 'read new message' (Figure 7) and 'reply' fields (Figure 8), maybe because the feedback was not adequate;

iii) in the 'write new message' field (Figure 9), the participants did not know where to write the subject. Contextual information may be necessary or a name change must take place;

iv) in the 'choose contacts' field (Figure 10), participants failed to proceed with the task, after having chosen contacts. This may indicate that the 'has chosen' button, which gives continuity to the task, requires review. The format should be simple and easy to follow so as to ensure that users understand what comes next (Bosman et al. 2002; Nielsen 2002; Zaphiris et al. 2005).

Furthermore, evaluation of the second version by the group of older adults from Maryland produced the following findings:

i) in the input area of the email interface (Figure 6), the placing of 'already read' messages in a new folder complicates the tasks. If a participant would like to read the message again, he/she has to go to a new folder, which only complicates matters further. In addition, messages that have not been read are highlighted differently, so it is not necessary to create another index separator in the upper right corner of the interface as in Figure 6;

ii) the use of different terminology confuses the user. The participants suggested that in the 'choose contacts' field (Figure 10), the problem of the term 'has chosen' can be solved if it is replaced by 'compose message' or 'write message'.

After collecting this data, reorganization of the graphical interface of the email was carried out in order to create a third version. The next evaluation phase was carried out while the email service was being integrated into the online community (under development within the SEDUCE project). Figures 11, 12, 13, 14 and 15 represent the graphical interface of the email service tested with seniors at IPSS A and IPSS B - third phase of testing. 
Both evaluation groups shared the findings of the tests applied to this third version. They demonstrate only that the scroll design did not work. Regarding the scroll problem, during the last session, the participants suggested putting triangular shapes on the top and bottom of the bounding box, to metaphorically represent the standard directional arrows to scroll emails in the inbox.

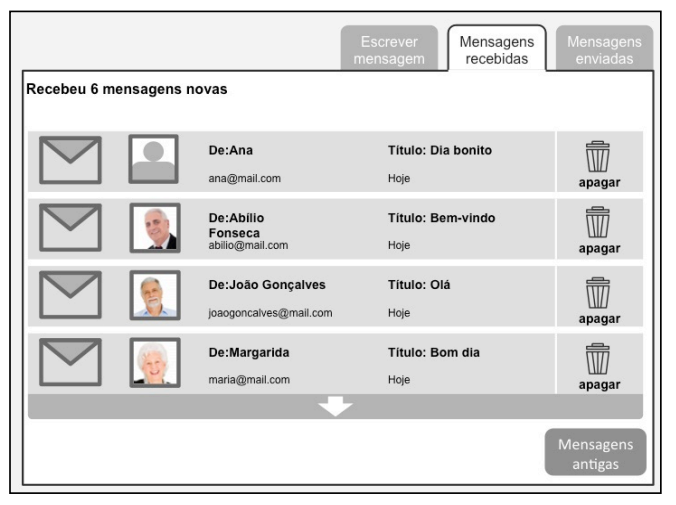

Figure 6. Interface layout of inbox area, 2nd version

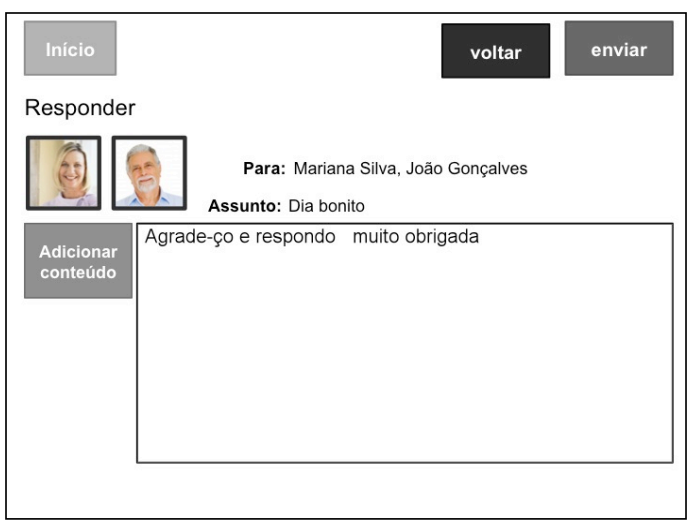

Figure 8. Interface layout of the 'reply' area, 2nd version

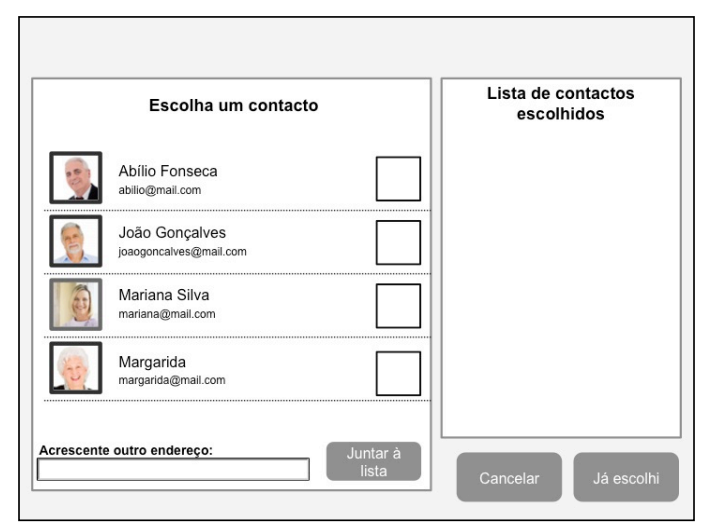

Figure 10. Interface of the 'choose contacts' area, 2nd version

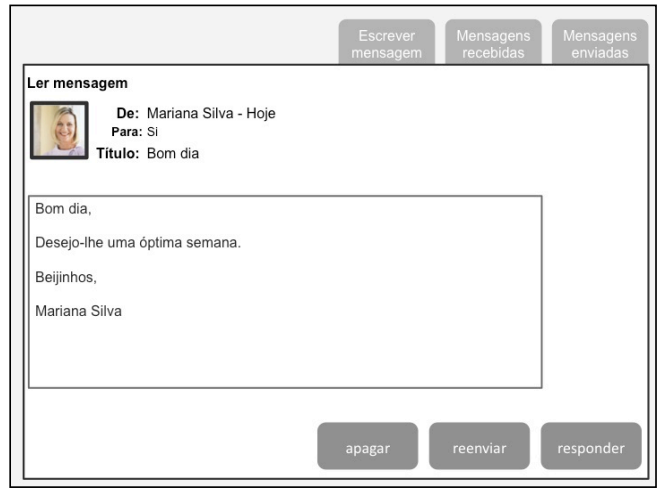

Figure 7. Interface layout of the 'read new message' area, 2nd version

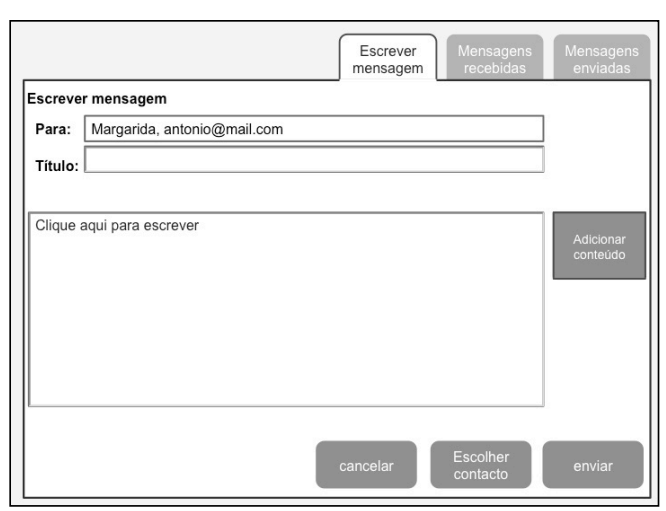

Figure 9. Interface layout of the 'write new message' area, 2nd version 


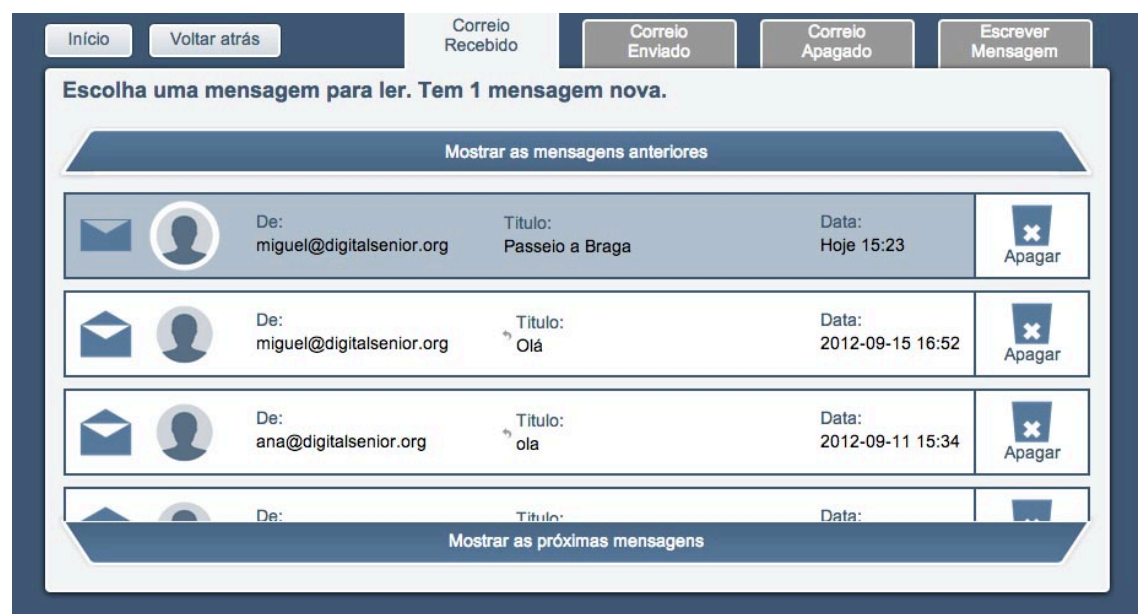

Figure 11. Interface of the input area, 3rd version

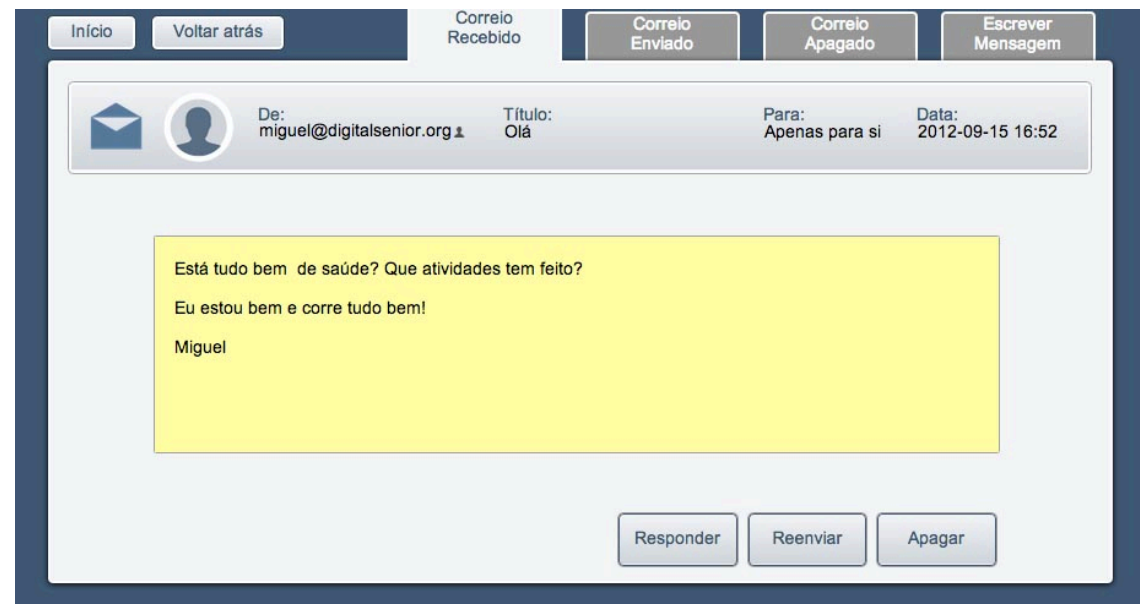

Figure 12. Interface of the 'read new email' area, 3rd version

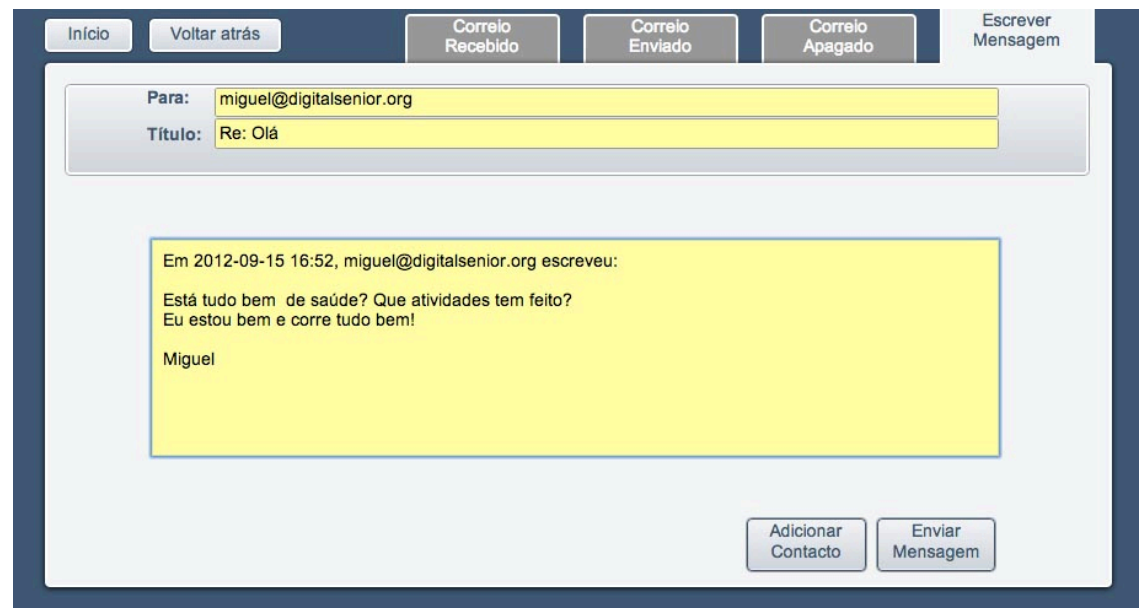

Figure 13. Interface of the 'reply' area, 3rd version 


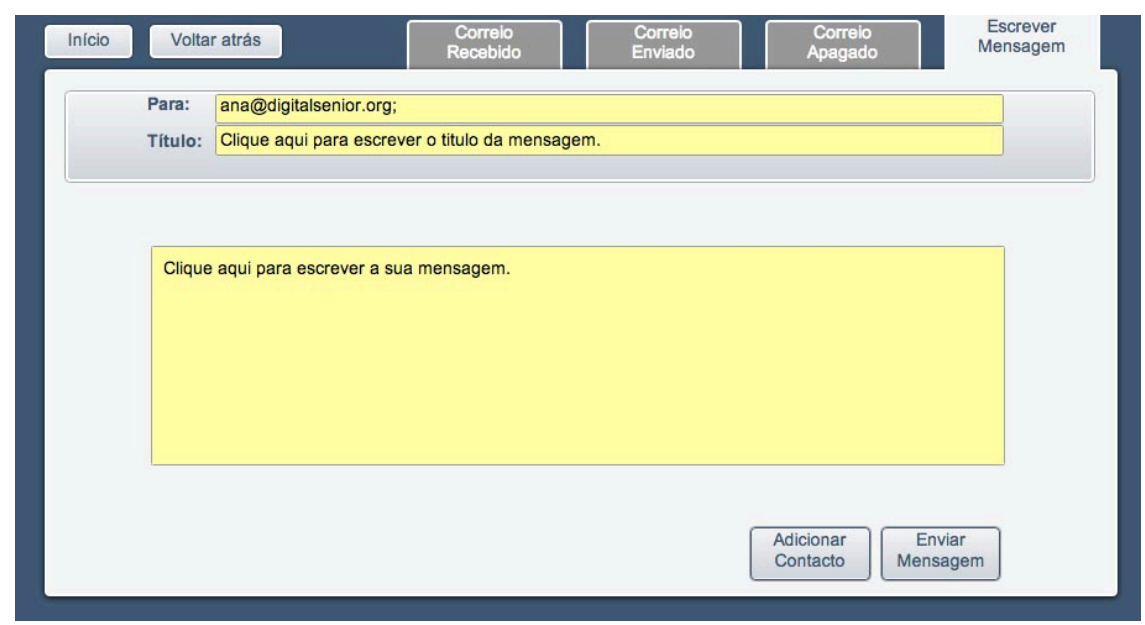

Figure 14. Interface of the 'write new message' area, 3rd version

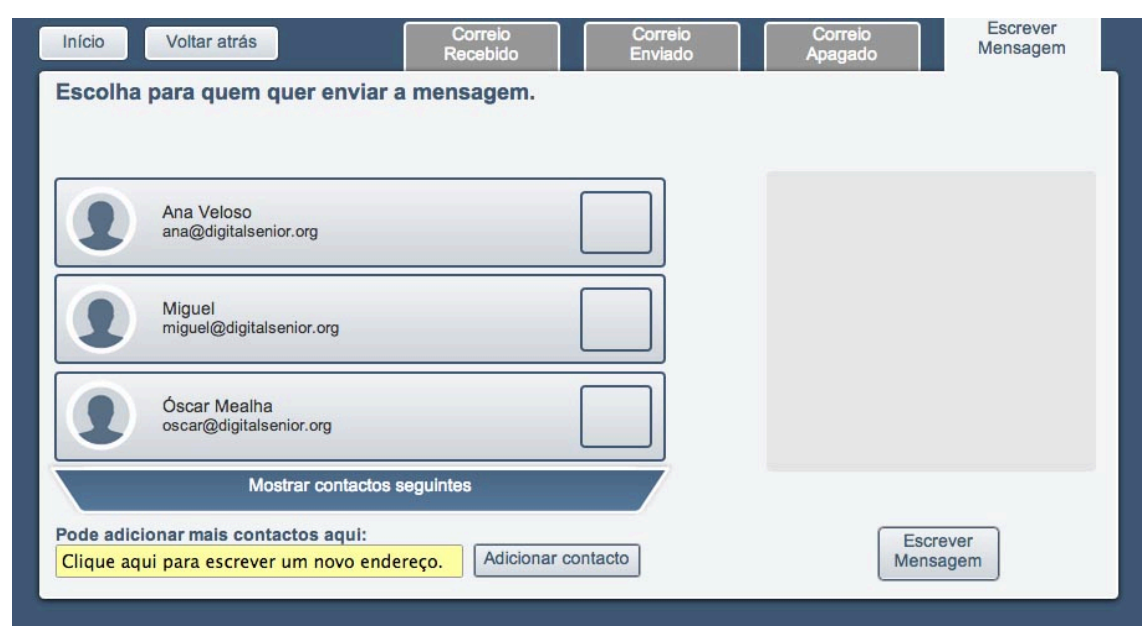

Figure 15. Interface of the 'choose contacts' area, 3rd version

\section{Specification and evaluation of the global usability of the email service}

According to ISO 9241 Part 11, to specify or measure the usability of a Communication Service, or any other product, it is necessary to identify its goals and values of effectiveness, efficiency and satisfaction. The purpose of an asynchronous communication service is to provide the user with a simplified and user-friendly interface to receive and send messages/emails.

Regarding the purpose of the present research, to understand whether the participation of older adults in the development of an email service can influence its usability, the usability findings from the development group were compared with those from the evaluation group. The test session was conducted by a scripted task, and involved participants at IPSS A and IPSS B, who were members of the development and evaluation groups, respectively. At IPSS A, the evaluation took place on September $11^{\text {th }}$ and $18^{\text {th }}$ and October $2^{\text {nd }}$ of 2012, in sessions lasting about 40 minutes. At IPSS B evaluation sessions were carried out on October $11^{\text {th }}$ and $18^{\text {th }}$ of 2012 , each one of them also last- 
ing 40 minutes. Results were recorded with the support of an observation grid, audiovisual recording and monitoring of activities using Screenium screen capture software.

The email service was evaluated according to the criteria of effectiveness (number of tasks completed successfully and number of errors), efficiency (time to complete the task and number of clicks) and satisfaction (ISO 1998). To evaluate the email service, the participants were instructed to perform the specific tasks shown in Table 5.

\begin{tabular}{cl}
\hline Task Number & Description \\
\hline T1 & View messages \\
T2 & Reply to incoming messages \\
T3 & Compose a new message \\
T4 & Select and add contacts \\
T5 & Read messages already read \\
T6 & Read deleted messages \\
\hline
\end{tabular}

Table 5. Summary of tasks

Figures 16, 17, 18, 19 and 20 show the results of the evaluation.

Overall, when comparing the results obtained from the development and evaluation groups, it appears that, although the evaluation group successfully completed more tasks and produced fewer errors (greater efficacy) in performing these tasks, an increasing amount of time and clicks are required (lower efficiency), but never in a different manner. Two members of the development group did not complete one of the tasks while four participants in the evaluation group completed all the tasks successfully (Figure 16). Participants in the development group made seven errors at various stages in tasks 1, 2, and 3. Participants in the evaluation group committed five errors. Participants in neither of the groups committed errors in tasks 4 and 5 (Figure 17). The errors made were concerned with the writing of the message title, use of the scroll and conclusion of the tasks. The average time spent by the participants in the development group (time $=30 \mathrm{~min} 20 \mathrm{~s}$ ) was less than for the evaluation group (time $=35 \mathrm{~min} 10 \mathrm{~s}$ ) (Figure 20).

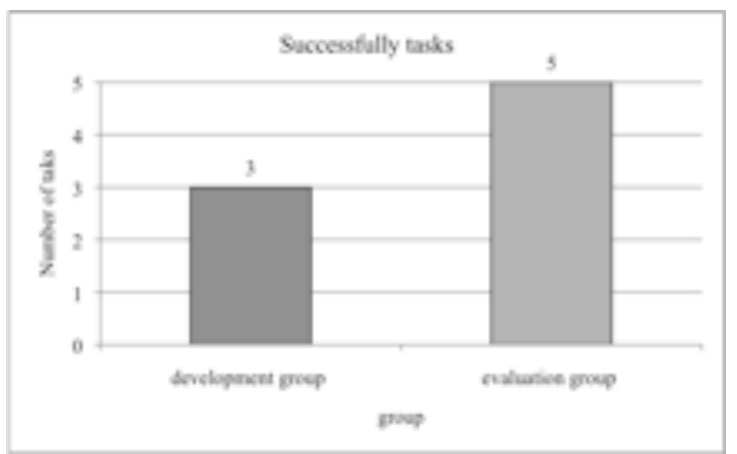

Figure 16. Number of successfully completed tasks

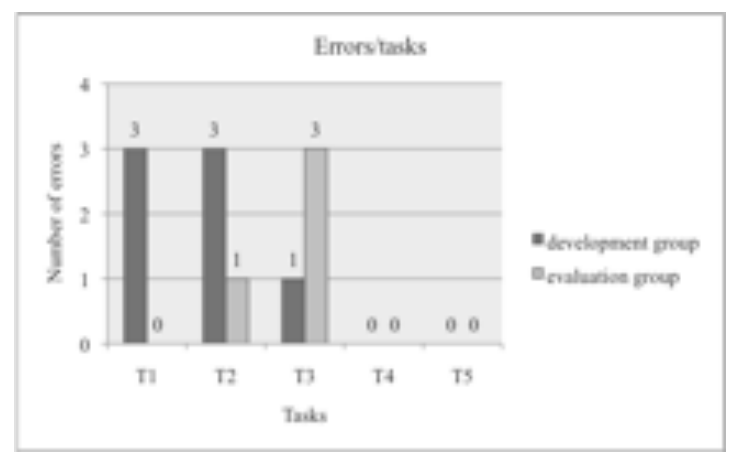

Figure 17. Number of errors per task 


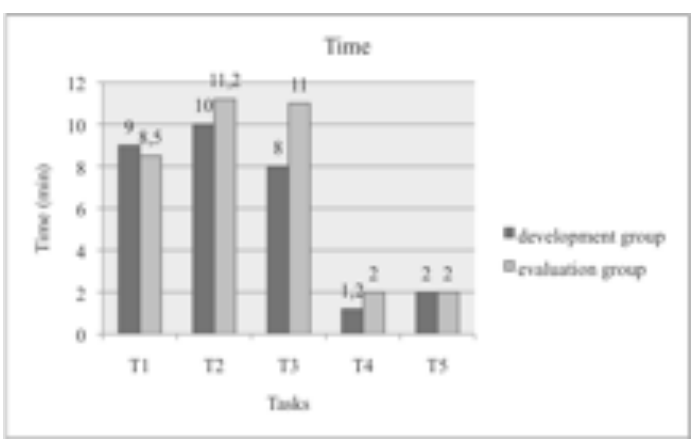

Figure 18. Time spent per task

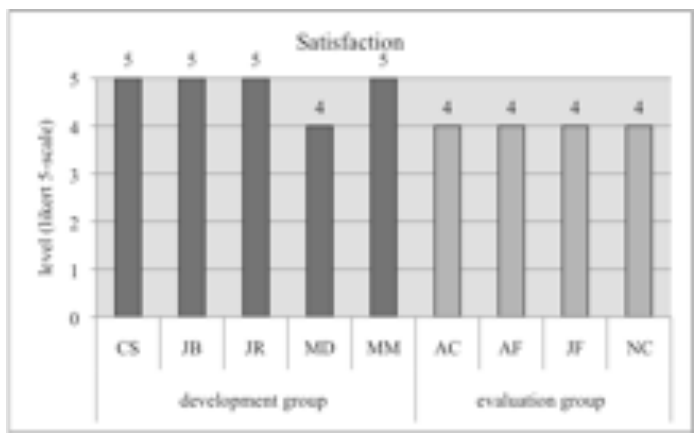

Figure 20. Level of satisfaction

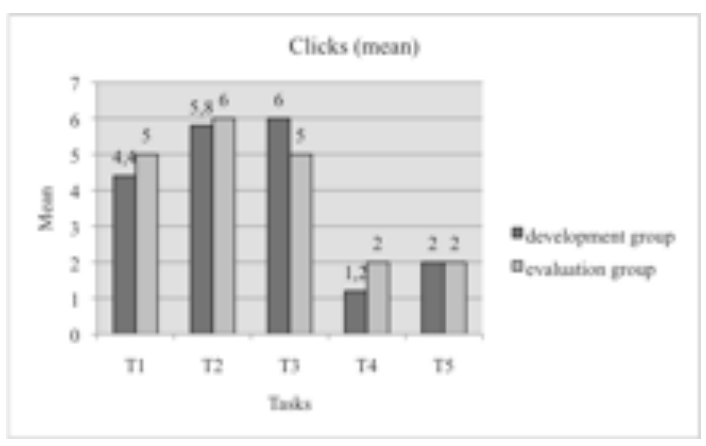

Figure 19. Mean of clicks per task

For more successful and effective task achievement, it would be necessary to make a total of 21 clicks in all the tasks: five clicks in the first task, six in the second, seven in the third, one in the fourth and two clicks in the last task. The first task can also be successfully completed in six clicks and the fourth with two clicks, although it is well known that the lower the effort in accomplishing the task, the greater the efficiency (ISO, 1998). Only one of the participants in the development group completed the task with the optimal number of clicks to achieve maximum efficiency, whereas in the evaluation group, two participants managed the same accomplishment (Figure 19).

Since it is a subjective satisfaction-oriented evaluation, each participant's performance has an impact on the final results presented. Given its subjective nature, evaluating participants' satisfaction (Figure 20) suggests that the level of satisfaction with the use of the prototype is high in both groups. However, it is noticeable that in the development group, the satisfaction is higher. Four of the five participants in the development group reported being "fully satisfied" with the prototype (likert 5-scale) whereas those in the evaluation group indicated they were "satisfied" (level 4 on a scale of 5).

\section{Discussion and conclusion}

This paper has presented an overview of the development of the graphical interface for an asynchronous communication service, email, co-designed for/with older users and incorporated in the SEDUCE project's senior online community - miOne (www.mione.pt). This study reveals that older adults' limited ICT experience and their 
lack of technical know-how can limit their critical thinking and, consequently, ability to come up with solutions.

Older adults in Maryland readily criticized the prototype, possibly because they frequently use ICT and email. Although older adults from Aveiro had more difficulty in expressing their opinion, they contributed significantly to the development of the prototype. Their lack of academic schooling allowed for greater questioning and reflection on what was presented to them. It was found that better practices are needed to enable older adults to participate in CMC. For example, interaction with seniors should be an iterative process that avoids the use of technical or formal language. Its purpose must, moreover, be clarified and seniors need to know that their performance is not being evaluated. In addition, they need to be given time to reflect and express their doubts and opinions.

As a developmental approach to services or products for older adult users, the contextual design (with co-design) process has proved to be a promising technique. Bearing in mind the limitations associated with the individuals participating in this study, and considering their low level of education and limited experience of ICT use, the contextual design option, that considered a co-design approach, allowed them not only to overcome difficulties but also to identify important clues for the future development of services and products for senior users. Some of the findings are corroborated by research by Nielsen (2002), Bosman et al. (2002) and Zaphiris et al. (2005) while this study contributes with the following recommendations:

- Language should be adjusted according to the users' characteristics, considering the particularities of the senior participants in this study, namely, their low level of education and lack of experience in using ICT. An example is the need to replace the titles of the fields for subject and for writing and composing the message;

- Contextual information should be supplied in the bounding box of messages describing features of different fields;

- The use of horizontal and vertical scroll bars should be avoided.

The results of measuring the effectiveness, efficiency and satisfaction of the evaluation group, according to statement of ISO 9241-11, are consistent with the results of the development group. The participants in the evaluation group were able to successfully complete more tasks and while they committed fewer errors, they took a long time to accomplish tasks.

The number of clicks is higher in the evaluation group but the difference is justified by the fact that completion of tasks necessarily requires more clicks than if they were not completed. Furthermore, the level of satisfaction for participants in the development group is higher than for those in the evaluation group, although both are high. Perhaps because the simple fact of participating in activities, as co-designers, different of their daily life routines, made them feel satisfied, with a sense of contribution to a project, 
and this interfered with the results of the interface evaluation, namely the satisfaction dimension.

\section{References}

Bengtson, V. L., Gans, D., Putney, N., and Silverstein, M. (2009) Handbook of Theories of Aging (2nd ed.). New York: Springer Publishing Company, LLC.

Beyer, H., and Holtzblatt, K. (1999) Contextual design. Interactions, 6(1), pp. 32-42. Doi: http://dx.doi.org/0.1145/291224.291229

Beyer, H. (2010) User-Centered Agile Methods (1 ed.): Morgan \& Claypool Publishers. Doi: http://dx.doi.org/10.2200/S00286ED1V01Y201002HCI010

Bosman, E., Charness, N., Czaja, S. J., Echt, K., Fisk, A. D., Kelley, C., ... Sharit, J. (2002) Making your Web Site senior friendly, Bethesda: National Institute on Aging and the National Library of Medicine.

Boyd, D., and Ellison, N. (2007) Social network sites: Definition, history and, scholarship. Journal of Computer-Mediated Communcation, 13(11). Doi:

http://dx.doi.org/10.1111/j.1083-6101.2007.00393.x

Brossoie, N. (2009) 'Social Gerontology', in R. Robnett and W. Chop (eds), Gerontology for the Health Care Professional, Sudbury, MA: Jones and Bartlett., pp. 19-52

Czaja, S., and Sharit, J. (2013) Designing training and instructional programs for older adults, New York: CRC Press Taylor \& Francis Group.

Czaja, S., and Lee, C. C. (2001) 'The Internet and Older Adults: Design, Challenges and Opportunities', in N. Charness, D. Park and B. Sabel (eds), Communication, Technology and Aging:

Opportunities and challenges for the future, New York: Springer Publishing Company, Inc., pp. 60-78

Cziko, G., \& Park, S. (2003) Internet audio communication for second language learning: A comparative review of six programs. Language Learning \& Technology, 7(1), pp.15-27.

Espanha, R. (2011) A Relação entre TIC, Utentes, Profissionais e Redes Tecnológicas de Gestão de Informação em Saúde. Lisboa: Centro de Investigação e Estudos em Sociologia, Instituto Universitário de Lisboa.

Ferreira, S. (2013) Tecnologias de informação e comunicação e o cidadão sénior: estudo sobre o impacto em variáveis psicossociais e a conceptualização de serviços com e para o cidadão sénior. Tese de doutoramento, Universidade de Aveiro.

Fonseca, I. (2011) O uso de dispositivos multitácteis para a infoinclusão do senior. Comunicação e Arte. Aveiro: Universidade de Aveiro, [online] Available at http://ria.ua.pt/handle/10773/6276. Acessed 15 June 2016.

Guerreiro, M. (2005) 'Avaliação neuropsicológica das doenças degenerativas', in A. Castro-Caldas and A. Mendonça (eds), A doença de Alzheimer e outras demências em Portugal, Lisboa, Portugal: Lidel, pp. 83-109 
Guerrieri, P., Bentivegna, S., and Meliciani, V. (2010) Analysis of e-Inclusion impact resulting from advanced R\&D based on economic modelling in relation to innovation capacity, capital formation, productivity, and empowerment. European Commission

Gross, E., Juvonen, J., and Gable, S. (2002) Internet Use and Well-Being in Adolescence. Journal of Social Issues, 58(1), pp. 75-90. Doi: http://dx.doi.org/10.1111/15404560.00249

Hernández-Encuentra, E., Pousada, M., and Gómez-Zúniga, B. (2009) ICT and older people: beyond usability. Educational Gerontology, 35(3), pp. 226-245. Doi: http://dx.doi.org/10.1080/03601270802466934

Hu, Y., Wood, J. F., Smith, V., \& Westbrook, N. (2004) Friendships through IM: Examining the Relationship between Instant Messaging and Intimacy. Journal of ComputerMediated Communication, 10(1). http://dx.doi.org/10.1111/j.1083-6101.2004.tb0023

ISO (1998) ISO 9241-11:1998 'Ergonomic requirements for office work with visual display terminals (VDTs) - Part 11: Guidance on usability', [online] Available at http://www.iso.org/iso/home/store/catalogue_tc/catalogue_detail.htm?csnumber=16877. Acessed 15 June 2016.

Kanayama, T. (2003) Ethnographic Research on the Experience of Japanese Elderly People Online. New Media \& Society, 5(2), pp. 267-288. Doi:

http://dx.doi.org/10.1177/1461444803005002007

Kim, H., Kim, G. J., Park, H. W., and Rice, R. E. (2007) Configurations of Relationships in Different Media: FtF, Email, Instant Messenger, Mobile Phone, and SMS. Journal of Computer-Mediated Communication, 12(4), pp. 1183-1207. Doi:

http://dx.doi.org/10.1111/j.1083-6101.2007.00369.x

Lima, M. (2010) Envelhecimento(s) - Estado da arte. Coimbra: Imprensa da Universidade de Coimbra.

Madden, M. (2010) Older Adults and Social MediaSocial networking use among those ages 50 and older nearly doubled over the past year. Washington, D.C. Pew Research Center.

Mitrea, P., and Mitrea, D. (2010) The role that Web 2.0 currently has and could have in the future in supporting the teaching of ICT design for all. Proceeding of First International Conference, Tech-Education 2010, Athens, Greece, May 2010, pp. 397-404. Doi: http://dx.doi.org/10.1007/978-3-642-13166-0_56

Morrison, J., and Barnett, A. (2013) 'Older people, technology and community: the potential of technology to help older people renew or develop social contacts and to actively engage in their communities', in IndependentAge (ed.), Supporting older people at home, London, pp. 1-38

Nielsen, J. (2002) Usability for Senior Citizens. Free Report. Available at http://district4.extension.ifas.ufl.edu/Tech/TechPubs/Usability4Seniors.pdf . Accessed 15 June 2016.

Nugent, C. D. (2007) ICT in the elderly and dementia. Aging \& Mental Health, 11(5), pp. 473-476. Doi: http://dx.doi.org/10.1080/13607860701643071 
Pfeil, U., Zaphiris, P., and Wilson, S. (2009) Online social support for older people: characteristics and dynamics of social support. Workshop Enhancing interaction spaces by social media for the elderly. Vienna.

Pires, A. T. (2008). Efeitos dos Videojogos nas Funções Cognitivas da Pessoa Idosa. Faculdade de Medicina. Porto: Faculdade de Medicina do Porto. Available at http://hdl.handle.net/10216/22139. Accessed 15 June 2016

Preece, J., Rogers, Y., and Sharp, H. (2005) Design de Interação: Além da Interação Homem-Computador. Porto Alegre: Bookman.

Preece, J., Rogers, Y., Sharp, H., Benyon, D., Holland, S., and Carey, T. (2005) Human-Computer Interaction. Addison-Wesley.

Prendergast, D. and Garattini, C. (2015) Aging and the digital life course. New York: Berghahn books.

Redish, J., and Chisnell, D. (2004) Designing Web Sites for Older Adults: A Review of Recent Literature. Washington, DC: AARP.

Rice, M., and Alm, N. (2008) Designing new interfaces for digital interactive television usable by older adults. Computers in Entertainment (CIE) - Social television and user interaction, 6(1). New York: ACM. Doi: http://dx.doi.org/10.1145/1350843.1350849

Santos, P. M., and Paúl, C. (2006) 'Desafios na saúde mental dos mais velhos', in H. Firmino, L. Pinto, A. Leuschner, and J. Barreto (eds), Psicogeriatria, Coimbra:

Psiquiatria Clínica, pp. 155-178

Sales, M. de, and Cybis, W. (2003) Development of a checklist for the evaluation of the web accessibility for the aged users. Proceedings of the Latin American conference on Human-computer interaction. Rio de Janeiro: ACM.

http://dx.doi.org/10.1145/944519.944533

Saxon, S., Etten, M., and Perkin, E. (2015) Physical change \& Aging - A guide for the helping professions. Springer Publishing company, LLC.

Simões, J. N. (2011) Proposta de um serviço de comunicação assíncrona para o cidadão sénior. Departamento de Comunicação e Arte. Aveiro: Universidade de Aveiro.

UMIC - Agência para a Sociedade do Conhecimento IP. (2010) 'Utilização de Internet em Portugal 2010. Lisboa: World Internet Project', [online], Available at http://www.umic.pt/images/stories/noticias/Relatorio_LINI_UMIC_InternetPT.pdf. Accessed 16 June 2016

Vaz-Serra, A. (2006) 'O que significa envelhecer?' in H. Firmino, A. Leuchner, and J. Barreto (eds), Psicogeriatria. Coimbra: Psiquiatria Clínica, pp. 21-33

Wright, K. (2000) Computer-mediated social support, older adults, and coping. Journal of Communication, 50(3), pp. 100-118. http://dx.doi.org/10.1111/j.1460-

2466.2000.tb02855.x

Xie, B. (2008) Multimodal Computer-Mediated Communication and Social Support among Older Chinese Internet Users. Journal of Computer-Mediated Communication, 13(3), pp. 728-750. Doi: http://dx.doi.org/10.1111/j.1083-6101.2008.00417.x

Zaphiris, P., Ghiawadwala, M. and Mughal, S. (2005) Age-centered research-based web design guidelines. in $\mathrm{CHI}$ ' 05 Extended Abstracts on Human Factors in Computing 
Systems (CHI EA '05). ACM, New York, NY, USA. Doi:

http://dx.doi.org/10.1145/1056808.1057050

Zickuhr, K., and Madden, M. (2012) Older adults and internet use. For the first time, half of adults ages 65 and older are online, Washington, 'Pew Research Center's Internet \& America Life Project', [online] Available at

http://pewinternet.org/Reports/2012/Older-adults-and-internet-use.aspx. Accessed 16 June 2016

Sónia Ferreira is Invited Adjunt Professor at School of Education and researcher at the Centre for the Study of Education, Technologies and Health - Polytechnic Institute of Viseu. She received her $\mathrm{PhD}$ in Information and Communication in Digital Platforms and her MSc in Multimedia Communication from the University of Aveiro (UA). She has been working as a researcher on the project SEDUCE- PTDC/CCICOM/111711/2009.From February to April 2012, Sónia has also participated in the project "Older Adults' Information Needs, Behaviors and Resources" coordinated by the professor Bo Xie, at the University of Maryland. Since September 2010, she has also been the co-organizer of the core television and of the annual video contest occurred in the ESE.

Email: soniaaf07@gmail.com

Ana Isabel Veloso is an Assistant Professor of the Department of Communication and Art and a member of the scientific board of the DigiMedia Research Center at the University of Aveiro. Throughout these years, Ana Veloso has been supervising many students of Master's and Doctoral degree levels. She has also been the coordinator of many research projects, such as SEDUCE (http://www.seduce.pt/SITE_EN/), EYES ON GAMES and IMP.cubed. She received her bachelor in Informatics Engineering (1992) and obtained her MsC in Biomedical Engineering (1996) from the University of Coimbra. She finished her doctoral studies in Communication Sciences and Technologies from the University of Aveiro, in 2006, with the thesis "The information and communication technologies in children's playfulness." Her research interests include digital games, information and communication in technological mediated contexts (design and evaluation for specific publics - children and seniors) and gerontechnology.

Email: aiv@ua.pt

Óscar Mealha is Associate Dean and a member of the scientific board at the centre of research CETAC.Media - department of Communication and Art, in the University of Aveiro. He received his $\mathrm{PhD}$ in Electronic engineering from the University of Aveiro (in 1995) and he has been working as a researcher in the areas of human-computer interaction (HCI), usability, information visualization for 20 years. Considering that period, sixteen years have been devoted to the area of information and communication sciences and Technologies.

E-mail: oem@ua.pt 